\title{
THE INFLUENCE OF POWER AND SOCIAL DISTANCE ON FAIRNESS PERCEPTION IN THE MULTIPLAYER ECONOMIC GAME
}

\author{
Xueying Li, Xilei Wang, Wenwu Dai, \& Ning Jia \\ College of education, Hebei Normal University (China)
}

\begin{abstract}
Objective: The goal of this research was to explore the influence of power and social distance on individual fair perception in the context of income. Methods: College students were selected to investigate and 197 answers, including 58 boys and 139 girls. Average age was 22.01 years $(\mathrm{SD}=2.52)$. The subjects were randomly divided into different groups, including 62 mothers ,75 friends and 60 strangers. The experimental design was 2[power: low power(be a responder), high power(be an allocators)] $\times 3$ [social distance: near (mother), middle (friend), far (stranger)] mixed experimental design. There is one allocator and two responders in the game. The experiment was divided into two subtasks according to the role of the participants: Subtask 1, stranger A is allocator, the participant is one responder, and the other responder is Mother/Friend/Stranger B. Subtask 2, the participant is allocator, stranger A is one responder, the other responder is still Mother/Friend/Stranger B. Results: (1) The participants had a lower sense of fairness to the same distribution scheme when their role changed from responder to allocator. (2) When friends and strangers got more money than themselves, the participants had a lower sense of fairness. (3) No matter what kind of distribution scheme, as long as the sum of the amount of money received by the participant and his mother is the same, he had the same fairness perception. Conclusion: First, the change of power will affect the individual's fair perception, and the higher demand for fairness after the power increases; Second, the influence of social distance reflects the characteristics of the Chinese self, that is, the self of Chinese people contains his/her mother.
\end{abstract}

Keywords: Power, social distance, fairness perception.

\section{Introduction}

Fairness is an important code of conduct of people's lives. Since ancient times, China has said that "Inequality rather than want is the cause of trouble ", and fairness has always been concerned by economists, sociologists and psychologists. Generally, people regard fairness as the rule in the process of material wealth distribution, which refers to the investment that people want in economic interaction is proportional to the result (Dijk \& Vermunt, 2000). In the field of psychology, researchers usually use the paradigm of economic game to explore the fairness perception when people face the problem of economic distribution. Previous studies have focused on single factors that affect fairness perception, such as subjects being less likely to accept unfair solutions at high power (Hu, Cao, Blue \&Zhou, 2014), or the fair perception of the subjects at low power is influenced by social distance from the allocator $(\mathrm{Wu}$, Leliveld \&Zhou, 2011) and so on. So, what is the change in the fair perception of individuals in the face of different social distance from their peers under different power? Therefore, this study aims to explore the influence of power and social distance on individual fair perception in the context of income.

\section{Method}

The experiment uses the questionnaire method, uses the ultimatum game variant to carry on the research. There were three participants in the game, subjects, strangers A with their mother / friend / stranger B. The experimental procedure is as follows: in the first stage, the stranger A become the distributor, while the subjects become the responder together with their mother / friend / stranger B, and the three people share 100 yuan. After defining the distribution scheme proposed by the stranger A (actually, the experiment has set the distribution scheme), the subjects need to judge the fairness grade of the scheme, and adopt the 7-point scoring method, from 1" very unfair "to 7" very fair ". The second stage, the subjects became allocators, strangers A responders with their mother / friend / stranger B, and the three still owned 100 yuan together. The subjects needed to evaluate the fairness of a series of distribution scheme as allocators. It's still a 7-point score.

The questionnaire star was used to carry out the online survey. First, the guide and the rules of the game were presented to the subjects to ensure that they understood the content of the game, and then the questionnaire was recovered after the completion of the answer. The whole process were about 5 minutes. 


\section{Results}

\subsection{Power perception differences in different roles}

Table 1. Power perception differences in different roles.

\begin{tabular}{ccccc}
\hline & low power & \multicolumn{2}{c}{ high power } \\
& $M$ & $S D$ & $M$ & $S D$ \\
\hline Mother Group & 3.35 & 1.344 & 5.40 & 1.166 \\
Friends Group & 3.80 & 1.461 & 5.52 & 1.319 \\
Stranger Group & 3.60 & 1.575 & 5.77 & 1.212 \\
\hline
\end{tabular}

The difference of power perception under different roles was significant, $F(1,194)=180.153$, $p<0.001, \eta_{p}{ }^{2}=0.481$. The main effect of social distance is not significant. The interaction between role and social distance is not significant. Demonstrate that power manipulation is effective.

\subsection{Perceptual differences in different schemes that get the same amount of money}

Table 2. Perceived differences in getting the same amount.

\begin{tabular}{lcccccccc}
\hline & \multicolumn{4}{c}{ low power } & \multicolumn{4}{c}{ high power } \\
& $40-30-30$ & \multicolumn{2}{c}{$60-30-10$} & \multicolumn{2}{c}{$30-40-30$} & $30-60-10$ \\
& $M$ & $S D$ & $M$ & $S D$ & $M$ & $S D$ & $M$ & $S D$ \\
\hline Mother Group & 4.68 & 1.423 & 2.71 & 1.298 & 4.15 & 1.213 & 2.63 & 1.218 \\
Friends Group & 4.49 & 1.178 & 2.59 & 1.128 & 4.36 & 1.311 & 2.40 & 1.040 \\
Stranger Group & 4.68 & 1.501 & 2.87 & 1.741 & 4.05 & 1.651 & 2.60 & 1.749 \\
\hline
\end{tabular}

With low power, the main effect of social distance is not significant. The main effect of the scheme is significant, $F(1,194)=247.990, p<0.001, \eta p 2=0.561$. The interaction between the program and the social distance is not significant.

With high power, the main effect of social distance is not significant. The main effect of the scheme are significant, $F(1,194)=171.461, \mathrm{p}<0.001, \eta p 2=0.469$. The interaction between the program and the social distance is not significant.

\subsection{Fair perception differences in different schemes that receive less money than peers}

Table 3. Fair perception of schemes that receive less money than their peers.

\begin{tabular}{ccccccccc}
\hline & \multicolumn{3}{c}{ 40-20-40 low power } & \multicolumn{2}{c}{ 60-10-30 } & \multicolumn{3}{c}{ high power } \\
& $M$ & $S D$ & $M$ & $S D$ & $M$ & $S D$ & $M$ & $S D$ \\
\hline Mother Group & 4.50 & 1.434 & 2.87 & 1.531 & 3.82 & 1.261 & 2.74 & 1.342 \\
Friends Group & 3.25 & 1.560 & 2.44 & 1.287 & 3.49 & 1.408 & 2.57 & 1.508 \\
Stranger Group & 2.85 & 1.745 & 2.27 & 1.849 & 3.12 & 1.748 & 2.28 & 1.658 \\
\hline
\end{tabular}

With low power, the main effect of social distance are significant, $F(2,194)=11.137, p<0.001$, $\eta_{p}{ }^{2}=0.103$. The main effect of the scheme are significant, $F(1,194)=90.712, p<0.001, \eta_{p}{ }^{2}=0.319$. The interaction between the program and the social distance are significant, $F(2,194)=8.584, p<0.001$, $\eta_{p}{ }^{2}=0.081$.

With high power, the main effect of social distance is significant, $F(2,194)=3.039, p=0.050$, $\eta_{p}{ }^{2}=0.030$. The main effect of the scheme is significant, $F(1,194)=84.347, p<0.001, \eta_{p}{ }^{2}=0.303$. The interaction between the program and the social distance is not significant.

\subsection{Fair perception differences in different schemes that receive more money than peers}

Table 4. Fair perception of schemes that receive more money than their peers.

\begin{tabular}{|c|c|c|c|c|c|c|c|c|}
\hline & \multicolumn{4}{|c|}{ low power } & \multicolumn{4}{|c|}{ high power } \\
\hline & \multicolumn{2}{|c|}{$40-40-20$} & \multicolumn{2}{|c|}{$60-30-10$} & \multicolumn{2}{|c|}{$40-40-20$} & \multicolumn{2}{|c|}{ 30-60-10 } \\
\hline & $M$ & $S D$ & $M$ & $S D$ & $M$ & $S D$ & $M$ & $S D$ \\
\hline Mother Group & 4.35 & 1.356 & 2.71 & 1.298 & 3.77 & 1.151 & 2.63 & 1.218 \\
\hline Friends Group & 3.76 & 1.364 & 2.59 & 1.128 & 3.41 & 1.316 & 2.40 & 1.040 \\
\hline Stranger Group & 4.00 & 1.697 & 2.87 & 1.741 & 3.65 & 1.538 & 2.60 & 1.749 \\
\hline
\end{tabular}

With low power, the main effect of social distance are not significant. The main effect of the scheme are significant, $F(1,194)=136.298, p<0.001, \eta_{p}{ }^{2}=0.413$. The interaction between the program and the social distance is not significant. 
With high power, the main effect of social distance are not significant. The main effect of the scheme are significant, $F(1,194)=108.363, p<0.001, \eta_{p}{ }^{2}=0.358$. The interaction between the program and the social distance is not significant.

\subsection{Differences in Fair Perception of Different Programs Consistent with the Summaries of Companion}

Table 5. Fair perception of a scheme for a total of 60 yuan.

\begin{tabular}{|c|c|c|c|c|c|c|c|c|c|c|c|c|}
\hline & \multicolumn{6}{|c|}{ low power } & \multicolumn{6}{|c|}{ high power } \\
\hline & \multicolumn{2}{|c|}{ 40-30-30 } & \multicolumn{2}{|c|}{$40-20-40$} & \multicolumn{2}{|c|}{$40-40-20$} & \multicolumn{2}{|c|}{$30-40-30$} & \multicolumn{2}{|c|}{$20-40-40$} & \multicolumn{2}{|c|}{$40-40-20$} \\
\hline & $M$ & $S D$ & $M$ & $S D$ & $M$ & $S D$ & $M$ & $S D$ & $M$ & $S D$ & $M$ & $S D$ \\
\hline Mother Group & 4.68 & 1.423 & 4.50 & 1.434 & 4.35 & 1.356 & 4.15 & 1.213 & 3.82 & 1.261 & 3.77 & 1.151 \\
\hline Friends Group & 4.49 & 1.178 & 3.25 & 1.560 & 3.76 & 1.364 & 4.36 & 1.311 & 3.49 & 1.408 & 3.41 & 1.316 \\
\hline Stranger Group & 4.68 & 1.501 & 2.85 & 1.745 & 4.00 & 1.697 & 4.05 & 1.651 & 3.12 & 1.748 & 3.65 & 1.538 \\
\hline
\end{tabular}

With low power, the main effect of social distance are significant, $F(2,194)=7.264, p=0.001$, $\eta_{p}{ }^{2}=0.070$. The main effect of the scheme are significant, $F(2,193)=44.170, p<0.001, \eta_{p}{ }^{2}=0.314$. The interaction between the program and the social distance is significant, $F(2,194)=20.175, p<0.001$, $\eta_{p}{ }^{2}=0.172$.

With high power, the main effect of social distance are not significant. The main effect of the scheme is significant, $F(2,193)=27.809, p<0.001, \eta_{p}{ }^{2}=0.224$. The interaction between the program and the social distance is significant, $F(2,194)=3.887, p=0.022, \eta_{p}{ }^{2}=0.039$.

\subsection{Differences in fair perception of the same scheme after power increases}

Table 6 Fair perception of 40-20-40 programmed when power increases.

\begin{tabular}{ccccc}
\hline & \multicolumn{2}{c}{ low power $40-20-40$} & \multicolumn{2}{c}{ high power 20-40-40 } \\
& $M$ & $S D$ & $M$ & $S D$ \\
\hline Mother Group & 4.50 & 1.434 & 3.82 & 1.261 \\
Friends Group & 3.25 & 1.560 & 3.49 & 1.408 \\
Stranger Group & 2.85 & 1.745 & 3.12 & 1.748 \\
\hline
\end{tabular}

The main effect of social distance are significant, $F(2,194)=13.276, p<0.001, \eta_{p}{ }^{2}=0.120$. The main effect of the scheme are not significant. The interaction between the program and the social distance is significant, $F(2,194)=6.810, p=0.001, \eta_{p}{ }^{2}=0.066$.

\section{Conclusion}

First, the change of power will affect the individual's fair perception, and the higher demand for fairness after the power increases; Second, the influence of social distance reflects the characteristics of the Chinese self, that is, the self of Chinese people contains his/her mother.

\section{References}

Dijk, E. V., \& Vermunt, R. (2000). Strategy and fairness in social decision making: sometimes it pays to be powerless. Journal of Experimental Social Psychology, 36(1), 1-25.

Hu, J., Cao, Y., Blue, P. R., \& Zhou, X. (2014). Low social status decreases the neural salience of unfairness. Frontiers in Behavioral Neuroscience, 8, 40.

Wu, Y., Leliveld, M. C., \& Zhou, X. (2011). Social distance modulates recipient's fairness consideration in the dictator game: An ERP study. Biological psychology, 88(2), 253-262. 